\title{
Changing Learning Ecologies in Early Childhood Teacher Education: From Technology to STEM Learning
}

\author{
Xinyun $\mathrm{Hu}$ \\ Department of Early Childhood Education, The Education University of \\ Hong Kong \\ xinyunhu@eduhk.hk
}

Nicola Yelland

Melbourne Graduate School of Education, 100 Leicester Street, Carlton $305^{2}$ nyelland@unimelb.edu.au

\begin{abstract}
This review examines the design cycles of innovation in response to changing policy, technological and practical imperatives. It begins with the initial creation of an information and communication technology course in an early childhood teacher education program and describes its evolution into a contemporary topic. Program changes occur because of policy-driven trends, including the expansion of the definition of what constitutes technology and the incorporation of innovations into curricula and pedagogical practices. We characterize these changes in three design cycles. In the first cycle, courses to prepare preservice teachers for early childhood centers focused primarily on computer-based skills. In the second cycle, new technologies were integrated into the curricula and teaching programs and incorporated into the practicum. In the third cycle, the principles and practices inherent to science, technology, engineering and mathematics (STEM) education were adopted to extend the role of new technologies in contemporary curricula and pedagogies. These new learning ecologies were characterized by the application of inter-disciplinary knowledge in authentic learning contexts. The reviewed case studies included students in three new technologies course projects in an early childhood teacher education program. The findings revealed that early childhood preservice teachers expected more opportunities to practice and apply new technologies in innovative learning spaces focused on STEM learning. Furthermore, they believed that university teacher education courses should
\end{abstract}


be applicable to practice-based contexts. The implications of this review inform the process of change in the design of teacher education programs from technology-based learning to the pedagogical innovations needed to prepare future teachers. It illustrates that new technologies for learning should consider changing learning ecologies in their design and implementation, and should support early childhood teachers in understanding and using child-centered pedagogical approaches.

\section{Keywords}

STEM - digital technologies - early childhood education - teacher education

The various means by which information and communication technology (ICT) can contribute to learning in early childhood education (ECE) have been increasingly recognized over the past decades. Cuban (2001) described ICT in ECE as "a benign addition" (p. 67) or, at best, a useful supplement to other resources in a child's early years of schooling. This view exemplifies that of research from the 1990s, which underestimated the potential of ICT in preschool settings. In response, Plowman and Stephen (2003) suggested that ICT is much more than "a benign addition." They used various types of ICT in playbased preschool contexts and argued that their use should be encouraged to maximize the facilitation of learning. The use of ICT became even more relevant as the range and mobility of new technologies expanded beyond laptops. The National Association for the Education of Young Children (NAEYC) revised its position statement on the use of interactive media as tools to support the development of young children in 2006: while it recognized the ubiquitous nature of technology, it was guarded in its encouragement of ICT use. Researchers have argued that digital play should be incorporated into school practices (e.g. Marsh et al., 2016). Research has also revealed that a major problem identified by early childhood (EC) educators is how to effectively integrate digital media and the popular culture of children's daily lives into play-based learning (Edwards, 2015).

1 Disclosure statement: No potential conflict of interest were reported by the authors. This work described in this article was supported by the Teaching Development Grant (Project bumer: T0124, To219) in the Education University of Hong Kong. 
A considerable body of evidence suggests that EC teachers remain reluctant to use ICT in preschool settings, and researchers have attributed this to insufficient training (Blackwell, Lauricella, Wartella, Robb, \& Schomburg, 2013; Dong, 2018; Plowman, Stephen, \& McPake, 2010; Wang \& Li, 2018). Research conducted on the effectiveness of teacher education on the use of ICT has shown that many courses do not lead to changes in teaching practices or the sustained uptake of ICT in early childhood centers and schools. The aim of this review was to explore the progress of the implementation of and innovation in an ICT-related course over the past 10 years to better understand the evolution of course design and learning outcomes for EC educators. We note that in contemporary times, the use of the term "information and communication technology" is increasingly being replaced by "new technologies" or "digital technologies"; in this paper, we use these terms interchangeably to refer to all new /digital technologies. In reviewing the research literature, we use ICT because it was the favored term at the time of publication. We believe that the responsibility of teacher education programs to integrate digital technologies into courses does not involve supporting specific technical knowledge; rather, it involves comprehensively developing early childhood educators' competence in preparing play-based learning experiences for young children.

\section{Literature Review}

The literature review is divided into two sections. The first explores the use of ICT in ECE, and the second reviews the more recent adoption of new digital technologies in EC teacher education contexts.

\subsection{ICT in Early Childhood Education}

In the early research on the use of information and communication technology (ICT) in ECE, "ICT" was often used primarily to refer to desktop computers (Bolstad, 2004a; Clements, Nastasi, \& Swaminathan, 1993; Plowman \& Stephen, 2007). In the last several decades, dramatic changes have occurred in the use of various technologies and digital media in homes and preschools. Available technologies now include digital toys, digital cameras, video cameras, projectors, laptops, the Internet, CD players, portable interactive whiteboards, mobile phones, touch-sensitive tablets and digital toys. Siraj-Blatchford and Siraj-Blatchford (2006) defined ICT as "anything which allows us to get information, to communicate with each other, or to have an effect on the environment using electronic or digital equipment" (p. 4). This broad definition allows for the adoption of technologies in flexible learning environments. 
Unlike other levels of education, ECE has a distinct culture that emphasizes learning through play (e.g. Plowman, Stephen, \& McPake, 2010; Marsh et al., 2016). Curricula and assessment practices are less prescriptive than in later years of schooling and not driven by a mandated curriculum. Accordingly, the use of ICT in early childhood education was conceptualized broadly to include devices such as digital cameras and video cameras, electronic keyboards, toys that simulate laptops and mobile phones. This broad view supports the notion that "a restricted view of technology, such as a focus on desktop computers, can lead to a restricted view of play" (Plowman et al., 2010, p. 16). With the most recent innovations in technologies providing increased support for mobility and collaborative use, such technologies are more easily integrated into playbased curriculum and activities.

More recently, the use of digital technologies in early childhood education has been related to an upsurge in interest in science, technology, engineering and mathematics (STEM) learning (the term "STEM" originated in the United States in 2005). Research indicates that STEM concepts have received increased attention in recent years and that this emphasis is likely to extend into the future job market. STEM is not a new concept in preschools; however, it does require an emphasis on interdisciplinary connections (McClure et al., 2017) and strengthening of the teaching of some specific disciplines, such as the use of technology to support science and engineering learning. Yelland, Drake and Sadler (2017) stated that STEM in early childhood education involved "... the creation of learning environments in which children's curiosity about the world can thrive via systematic, authentic investigations that utilize a range of design thinking skills and scientific knowledge and processes which forms a useful foundation for educators to design exemplary sт EM learning activities in the preschool years" (p. 3). Historically, EC teachers' low self-confidence in the sciences negatively influenced their perceived ability to participate in EC STEM teaching, which affected its likelihood of being incorporated into ECE programs. The use of digital technologies in STEM learning is also changing from an emphasis on learning about technology to more of a focus on the innovative uses of digital technologies to explore the world (The Early Childhood STEM Working Group, 2017). Wang and Li (2018) suggested that early childhood teachers should be supported with practical ideas about how to include digital technologies in their planned play-based experiences. In is thus apparent that digital technologies in STEM learning should be used to explore relevant mathematical, scientific and engineering problems.

Teachers play an important role in STEM education. Bers, Seddighin and Sullivan (2013) found that one factor in the lack of teaching of technology and engineering in ECE is that many teachers are unfamiliar with 
technology and engineering concepts. English (2018) argued that teachers must learn new engineering design concepts when implementing STEM education in primary schools. Her research revealed that the omission of engineering experience in primary grades was in part due to the stereotyping of engineering as complex and difficult to teach and learn. However, other research suggested that young learners are capable of applying STEM concepts, such as by building optical instruments (King \& English, 2016).

\subsection{ICT Related Courses in EC Teacher Education}

In the last decade, teacher education programs have focused on the increased use of digital technologies for teaching and learning. Previously, attitudes toward new technologies in general were a pertinent factor in shaping the use of digital technologies in centers and classrooms. Rosen and Jaruszewicz (2009) developed a framework called "developmentally appropriate technology use" (DATU) to support EC teachers in the use of new technologies. According to DATU, any consideration of digital technologies with young children should include equipment, communication and interactive applications that encourage collaborative problem-solving in play and inquiry-based learning environments. In such contexts, new technologies are relevant when they capitalize on a child's natural desire to actively and collaboratively construct knowledge and when it respects the unique challenges that children face as they develop. The DATU framework takes into account that children are active constructors of knowledge and that development and learning result from interactive processes. EC professionals are advised to use their knowledge about how young children learn to create environments that support the integration of new technologies in ways that are relevant to the children's needs and interests to help them understand and communicate ideas.

With the increasing use of technology in preschool settings, teacher education programs began to include mobile technologies in their design. Ainsa (2013) reported that an ECE program was implementing "four levels of engagement" for mobile technologies. At level 1, $27 \%$ of student EC teachers were interested in teaching with mobile devices. At level 2, $27 \%$ of student EC teachers attended an informative workshop and participated in discussions about new teaching methodologies and possible applications (apps) that could be used for teaching. At level 3, 7\% of EC teachers planned a lesson that would require them to use mobile devices to teach. Finally, at level 4, a few (4\%) implemented their lesson plans or used apps and mobile devices in their classrooms.

Another suggested method for preparing EC teachers to teach is to improve their knowledge about possible technology integrations in project-based 
learning projects. Alexander et al. (2014) introduced a method that was linked with project-based learning to develop the attitudes and skills of EC teachers. The STEM Semantic Survey, Technology Proficiency Self-Assessment questionnaire and the Stages of Adoption of Technology in Education questionnaire were applied at the beginning and the end of teaching. The results showed positive changes in the attitudes and perceived skills of preservice educators toward STEM.

\section{Context for the Use of Technology in Preschools in Hong Kong}

Three strategic plans for ICT policy in schools have been launched in Hong Kong since 1998. However, there are no current guidelines or specific policy documents for the use of ICT at the preschool level.

ICT first appeared in the domain of science and technology in 2006 in the Guide to the Pre-Primary Curriculum (The Curriculum Development Council [CDC], 2006). This document considered ICT to be any product or resource that relates to a child's daily life, but it provided no specific guidance for the pedagogical use of ICT in the curriculum. The recommendation merely classified technology as a component of the general curriculum. In the revised kindergarten curriculum guide launched in 2017 (CDC, 2017), one of the key learning areas, "Science and Technology," was renamed "Nature and Living." This change was made to improve curriculum integration to avoid confusion in the subject-based curriculum framework. Digital technology is still regarded as a teaching aid for teachers and as technical products for children. Hence, there are no guidelines in Hong Kong on the pedagogical role of ICT in ECE or for how the preferred pedagogical activities might be adopted when ICT is used. It has become apparent that EC teachers should independently decide whether and how to include technology in their pedagogical repertoire.

Hong Kong has adopted a child-centered educational ideology for early childhood teaching contexts and has encouraged participation in curriculum development to help teachers deal with the complexities of local education reform (Ho, 2010). Schools and teachers concurrently drive curriculum development. However, Asian cultural influences shape educational discourses, and curriculum and teaching methods largely remain didactic and traditional. In such learning environments, classrooms are highly centralized and teacher-student interaction is hierarchical and collectivistic (Biggs, 1998). The idea of child centeredness embodied in government guidelines for ECE 
does not fit easily with teacher dominance, which is embedded in the practice of preschool teaching. Hu and Yelland (2017) investigated how 15 preservice EC teachers adopted ICT after completing an ICT-related course. The data, which were collected during a teaching practicum period, revealed that few child-directed activities were adopted in a teacher-directed approach to learning. The teaching context allowed for few child-directed activities and few child-initiated activities integrating Іст. These findings indicate that ECE teachers need more support in actual practice in school settings. School factors such as school-level curricula, ICT infrastructure and school-level ICT vision should be considered in teacher education to guide teachers in preparing appropriate ICT-related pedagogical approaches in their specific school contexts.

\subsection{Research Method}

We use multiple case studies as the methodological approach in this review, as they allow us to focus on the three cycles of design. We consider three ICT related course projects in the teacher education program that were designed and implemented from 2006 to 2018. Data from ICT-related courses taught during 2006-2007, 2010-2011 and 2016-2017 were collected as cases, and these data are presented in this paper to represent the three iterations of design thinking. The selected years were the first year of course innovation for each project.

This review considers the course level and the EC teacher level. At the course level, formal course documents were collected from the early childhood department's course resource boxes, including course outlines, course progress reports and reflective reports. Notes from course meetings were collected from the lecturers as a second source of design-related feedback. At the EC teachers' level, the ICT-related activity plans and reflections were collected as documents. Analyses of these data and the EC student teachers' open-ended feedback were used to understand the factors that influence the adoption of ICT. Multiple data resources were collected in this study to (1) analyze ICTrelated course resources, (2) identify core attributes using the EC teachers' feedback, (3) collect results from the specific cycle and (4) identify a new core action.

\subsection{Research Questions}

What changes occurred in the course design in the three cycles, and what core attributes were associated with these changes?

What did the feedback reveal about the ICT integration for preparing future teachers? 


\section{$4 \quad$ Findings}

\subsection{First Cycle: From “Computer" to "ICT" (2006-2009)}

From 2006 to 2009, the teacher education program offered a compulsory course ( 3 credits) called Computer Application in Early Childhood Education, in which students explored the use of computer-related technologies in ECE. The course was renamed Information Technology in ECE Curriculum in the second semester of 2009 .

At the time, the Guide to the Pre-Primary Curriculum suggested that preschools should balance the time that they spent on ICT with children's other daily activities:

Time spent on using technological products (such as computers) as teaching aids should not be too long, so as not to hinder the overall teaching arrangements ... over-dependence on technology will deprive children of opportunities to learn from reality. (CDC, 2006, p. 32)

This general advice in the curriculum guide was considered by many to have a potentially negative impact on the use of ICT. There was no policy or curriculum guideline governing the use of computer activities by teachers in schools either then or now. The main purposes of the subject were to help teachers become familiar with ICT and to encourage them to think about ways of using ICT in EC teaching and learning settings. Teachers learned the theoretical background of ICT and how it might influence children's learning, and they were also shown ways to apply technology in the teaching and learning context. It is apparent that at the time, teachers were being asked to understand the criteria for selecting appropriate educational technologies and Internet resources. In the course, preservice teachers focused on understanding what types of ICT could be used, and their major learning objective was to improve their technological skills. The three learning objectives were as follows.

Why should ICт be used? Teachers should know why they should use the computer in their teaching activities. Teachers should analyze teaching objectives and identify the computer that can be used in their instruction based on children's needs.

How should ICт be used? Teachers should know how to apply the computer to create multiple learning resources for young children's learning. Furthermore, teachers should be competent in planning and implementing computers to support the learning.

Which ICTs should be used? Teachers should learn to use computers, software and Internet-based resources to deliver learning resources. 


\subsubsection{Feedback from the First Cycle}

The course evaluation forms from the EC preservice teachers were open coded, and two positive aspects were repeatedly mentioned. First, with regard to technological knowledge, the EC preservice teachers felt that the course provided professional knowledge and support for them to deliver learning resources, such as by creating movies and pictures. They also found Internet resources useful for preparing activities. Second, regarding technological pedagogical knowledge, the EC preservice teachers indicated that they appreciated the practical workshops, as the course prepared them to search for useful information, to produce multiple learning resources, including sounds, and to present their learning content attractively using the computer and accessories. A broad definition of ICT was requested by both teacher educators and EC teachers in this cycle. User-friendly technologies for promoting children's exploration were introduced in the course, such as interactive whiteboards, digital cameras, Internet searching and digital toys. However, EC teachers mentioned that they lacked classroom experience when they went on practicum; they required more practical opportunities in school contexts to apply these technologies in real classroom settings. Thus, the need for more practice using ICT was identified as a core attribute in this cycle.

\subsection{Second Cycle: Integrating Ict in the Teaching Practicum (2009-2016)} Integrating ICT in classroom practice was the key activity during this period. It went beyond teachers knowing what was available in terms of the use of ICT in EC programs to thinking about more creative ways to enrich the existing curriculum by integrating ICT into their planned learning activities. Thus, in the second cycle, EC student teachers were guided to design ICT-related activities and to implement them into their pedagogical designs for their classrooms as part of the course assessment. This course was designed to equip EC teachers to design, implement and evaluate the effectiveness of ICT-related learning activities for young children in the school context.

Why should ICT be used? ICT implementation encouraged EC teachers to shift their view beyond usage to the potential for integrating technology into early childhood education programs. Preservice teachers needed to identify the influence of ICT and think about how it could affect children's social, communicative, intellectual and creative development.

How should ICT be used? To explore how ICT can support young children's learning in different areas, the EC preservice teachers were guided to use ICT to enhance children's play experiences. This was at the core of the curriculum framework, which defined six learning areas.: "Physical Fitness and Health," "Language," "Early Mathematics," "Science and Technology," "Self and Society" and "Arts" (Curriculum Development Council, 2006, p. 16). These learning 
areas are interrelated, and the use of ICT was specifically aimed at integrating all of these learning areas.

What ICTs should be used? The provision of ICT in the school context was regarded as an important factor affecting its use in teaching. Documentation revealed that teachers should identify the needs and the potential of each school to design and illustrate how ICT can be integrated into learning activities to support children's learning.

\subsubsection{Feedback from the Second Cycle}

The core attributor for the second cycle was to link the pedagogical practices of ICT with the school conditions. It was considered essential that all of the uses of ICT and the problem-based scenarios generated should be connected with the local school settings, especially school-based conditions that may affect EC teachers' decision making regarding the use of ICT. However, EC teachers' feedback showed that they had few options in terms of the ICT activities that could be used in school.

Documentation from the EC preservice teachers indicated that the learning content and resources were well prepared and organized, with resources presented using the computer and projector. However, teachers incorporated technologies that were limited by the school ICT infrastructure. The computer and CD player were frequently used to deliver digital learning resources via such as PowerPoint presentations, videos, pictures and audio. However, the EC teachers found few opportunities to allow children to access information on the Internet during large-group direct teaching. The teachers had limited authority to decide the learning objectives and content of the structured curriculum, and additional school-level factors such as large group sizes and fixed spaces also affected their willingness to use ICT.

The data revealed that the integration of ICT in the school context was linked with the practices advocated in the teacher education program; however, the school-context ICT conditions did not provide positive support for teachers to adopt ICT across the curriculum. This was especially the case with innovative technologies that were limited in local school systems. Technology in preschools was still considered an additional resource for teachers to deliver learning content, but children had few opportunities to explore it even though the policy called for integration.

\subsection{Third Cycle: Designing Technology and the Use of Digital Resources in the STEM Learning Context (2016-2018)}

In Hong Kong, there is an increasing need to expose children to science, technology, engineering, and math (STEM) in school settings. It has been advocated that early childhood teacher education programs integrate STEM 
with professional development, but there is a lack of professional development resources for supporting early childhood educators. The implications of STEM learning for EC teachers are relevant because they are based on the assumption that it is important to prepare young children for the world by providing them with access to high-quality STEM experiences in their early years. In the third cycle, the course aimed to guide EC teachers to plan, design and implement STEM-related learning activities in preschool contexts. Given the densely packed nature of the current EC curriculum, many EC teachers feel that STEM content is an extra dimension that they do not have time for their busy schedules. However, they are being taught to view STEM as a new way of thinking and organizing curricula and pedagogies.

\subsubsection{Why Use Technology and Digital Resources?}

The role of technology in the STEM learning context is changing. In a policy report by the Early Childhood stem Working Group, technology is not considered a specific content area, but an important resource for exploring other learning areas.

We hold that the "T" in STEM — technology—should be considered differently from the other disciplines. Technology is not a content area to be studied by young children but rather an important tool that can support learning in the STEM disciplines and across the curriculum. In using digital technologies with young children, we recommend a progression that begins with learning how to use technology tools in the same way that we promote bookhandling skills in early literacy (Early Childhood sTEM Working Group, 2017, page 9).

\subsubsection{How Should New Technologies be Used?}

EC teachers were guided to design digital resources for STEM learning contexts to create ecologies that focused on new and dynamic multimodal experiences among children, their teachers and the materials. Multimodal learning incorporates visual, linguistic, aural, kinesthetic (tactile) and gestural ways of knowing and being. The use of new technologies affects each of these aspects and increases the number of possible ways to represent and communicate understanding about the world. Children can use a range of resources to explore their lifeworlds and can include new technologies in the process. It was thus hoped that the children's interactions with digital media would support exploration, discovery, documentation, research, communication and collaboration literacy (Early Childhood sT EM Working Group, 2017, page 9). 


\subsubsection{What New Technologies Should be Used?}

This course explored preparation for technology in STEM learning activities. Multiple new technologies were included as learning content, such as the computer and computer accessories. More emphasis was placed on digital resources that had the potential to promote children's motivation to learn, such as specific apps and digital toys.

Table 1 lists the examples collected from EC teachers' activity design. Based on the analysis, the roles of technologies were identified in five aspects, including technology for inquiring, exploring, creating, coding and documenting.

TABLE 1 Example of integrating new technologies in the course (2016-2017)

\begin{tabular}{|c|c|c|}
\hline $\begin{array}{l}\text { The role of } \\
\text { technology }\end{array}$ & STEM learning context & $\begin{array}{l}\text { Technology and } \\
\text { digital resources }\end{array}$ \\
\hline $\begin{array}{l}\text { Technology for } \\
\text { inquiring }\end{array}$ & $\begin{array}{l}\text { Children use WhatsApp to interview } \\
\text { a gardener to learn how to plant trees. } \\
\text { They use the Internet to obtain } \\
\text { virtual resources for planting trees. }\end{array}$ & Social media, Internet \\
\hline $\begin{array}{l}\text { Technology for } \\
\text { exploring }\end{array}$ & $\begin{array}{l}\text { Children use a digital microscope } \\
\text { to explore objects, such as a leaf. }\end{array}$ & $\begin{array}{l}\text { Digital microscope, } \\
\text { electronic balance, } \\
\text { digital magnifier, } \\
\text { digital globe, Inter- } \\
\text { net, digital books }\end{array}$ \\
\hline $\begin{array}{l}\text { Technology for } \\
\text { creating }\end{array}$ & $\begin{array}{l}\text { Children are guided to make a } \\
\text { digital book by using their own } \\
\text { painting (e.g. trees, leaves and their } \\
\text { own findings in the park) } \\
\text { Children create an Augmented } \\
\text { Reality (AR) garden. }\end{array}$ & $\begin{array}{l}\text { App: Book Creator } \\
\text { Website: Story } \\
\text { Jumper } \\
\text { App: } 3 \text { D-bear }\end{array}$ \\
\hline $\begin{array}{l}\text { Technology for } \\
\text { coding }\end{array}$ & $\begin{array}{l}\text { Children use a coding toy to play the } \\
\text { game "The Very Hungry Caterpillar" } \\
\text { and create a coding map. }\end{array}$ & $\begin{array}{l}\text { Coding toy } \\
\text { (e.g. Code-a-Pillar } \\
\text { Coding Caterpillar) } \\
\text { BeeBot map }\end{array}$ \\
\hline $\begin{array}{l}\text { Technology for } \\
\text { documenting }\end{array}$ & $\begin{array}{l}\text { Children use the digital camera } \\
\text { to record various leaves and trees } \\
\text { in the park. } \\
\text { Children use the iPad to record their } \\
\text { findings and performance. }\end{array}$ & $\begin{array}{l}\text { Digital camera, iPad, } \\
\text { Mobile phone }\end{array}$ \\
\hline
\end{tabular}




\subsection{Feedback from the Third Cycle}

EC teachers showed many positive attitudes toward stem learning. The consensus was that STEM learning is essential for young children's holistic development and should be based in authentic inquiry. In the activity design process, the teachers said that it was difficult to determine what STEM concepts were appropriate and were unsure about how to initiate inquiries about them with young children. This was attributed to their limited training background, especially in the engineering and science disciplines. They recognized the need for more practical guidance to understand what to learn using age-appropriate practices in the teacher education program. The EC preservice teachers' report indicated that they required more demonstrations of real practices to become competent in the many ways of integrating technology in children's play-based learning scenarios. They also noted that a virtual learning experience was useful only for understanding the basic concepts. They also wanted more practical workshops. However, the teacher educator indicated that the university ICTrelated course was lacking in STEM learning resources, and EC teachers had only limited experience in applying these technologies and digital resources during learning.

EC teachers also reported that the technology and digital resources varied considerably between preschools. Some schools offered rich technology infrastructure: in addition to desktop computers, the preschools were equipped with ICT peripherals, such as laptop computers, digital cameras, printers, digital videos, iPads and interactive TV. Some preschools required teachers to share this additional ICT equipment across all classrooms. Many resources were provided to support teaching, but teachers often lacked ideas about what the children's involvement would look like. However, the EC preservice teachers said that they felt comfortable bringing their own mobile devices, such as iPads and mobile phones, to support learning. They also said that they expected the preschools to provide more resources for them to practice, such as iPads and a wider range of iPad games.

Given the nature of the curriculum and pedagogy in preschools, the integration of technologies and digital resources into classroom practice has been complex. The data analyzed here reveal the core attributes of the three cycles:

The first cycle: Extending the definition of ICT beyond a skills-based approach.

The second cycle: Integrating the adopted technologies in the teaching practicum.

The third cycle: Creating more practical and authentic learning opportunities in STEM learning ecologies. 
The changing definition of "technology" in ECE was an important reason for the course changes and approaches that occurred over the decade under review here. The course first adopted a definition of ICT that included computerbased technologies in the first cycle. The focus on skill building then shifted to a more progressive approach requiring a broader view of learning ecologies. The ways in which the various technologies and applications that may contribute to children's learning was apparent in the second cycle because of the idea of integrating approaches via independent learning. It aligned with the concept of ICT given by Siraj-Blatchford and Siraj-Blatchford (2006), which included "anything which allows us to get information, to communicate with each other, or to have an effect on the environment using electronic or digital equipment" (p. 4). For instance, this course adopted the statement by the NAEYC (2012) that the definition of ICT extended to both "technology and interactive media." It has long been said that children's learning about ICT must go beyond the development of the fundamental skills of operation (Buckleitner, 2009). Using child-friendly software programs, children were able to design their own business cards with assistance from a teacher. Other exciting technology learning experiences for young students included the use of digital cameras (Carter Ching, Wang \& Kedem, 2006), printers and scanners (Wilson et al., 2003), interactive whiteboards and programmable toys (Price, 2009). These and other learning technologies allow children to explore beyond the functionality of the technology, especially when the interface is child-friendly.

Overall, it is apparent that EC preservice teachers were able to use digital technologies during their teaching practicum by integrating what they had learned in their teacher education programs in limited ways in real-world scenarios. In the first teaching practicum, when EC teachers had to design and implement an ICT activity to fulfil the course requirement, the teachers provided children with opportunities to use ICT, including computers, digital cameras and other devices, to support learning.

Public awareness of the importance of innovation in STEM education is increasing, and STEM education has been a key emphasis in the ongoing renewal of the school curriculum in Hong Kong (The Curriculum Development Council, 2015). The promotion of STEM education in the early years aligns with the worldwide education trend of innovation to equip young children to explore STEM concepts in their daily exploration (Counsel, 2016).

EC teachers showed positive attitudes toward learning about technologies and digital resources in STEM learning ecologies. The four STEM disciplines 
were already included in Hong Kong's EC curriculum. For example, mathematics and science learning goals are well established in the curriculum guide. Engineering, despite not having any specific teaching program, is well integrated into EC environments. For example, the block area is one of the most popular areas for children to play in, and toys such as Lego that focus on construction and design fully integrate fundamental engineering concepts. Therefore, the basic concepts of STEM already exist in children's daily learning experiences. Consequently, initial steps for preparing for STEM learning can include reviewing current learning approaches. Practitioners may realize that they already have the basic elements for teaching sтEM. The next steps are to improve discipline-specific content knowledge and explore interdisciplinary connections.

Adopting STEM in the curriculum can be considered an innovation in early childhood education at the levels of both learning content and pedagogy in Hong Kong. However, high-quality STEM education has not yet been integrated into teacher education. For all children to have access to high-quality ST EM experiences in preschool, their teachers need to be well equipped in both knowledge content and pedagogy to provide high-quality STEM experiences in their classrooms (Early Childhood stem Working Group, 2017). Preschool settings should also support EC teachers in planning, designing and implementing their own curricula and pedagogies in the STEM learning context.

Consideration of how new technologies can be used to support learning is essential for the future of teacher education in Hong Kong. Teachers' technological competences are important, especially when they require need rich digital resources for their daily design of learning experiences. In thinking about the design of teacher education programs, teacher educators need to rethink the systematic ways of preparing for future learning ecologies. Based on the three cycles of practice considered here, the teacher education program should include creating new learning experiences for equipping future teachers to incorporate new technologies and appropriate digital resources into learning to provide project-based authentic inquiries that characterize STEM learning ecologies.

We believe that the components for effective STEM learning experiences can be encapsulated in the model proposed here based on this review (see Figure 1). The components are outlined and begin with the child at the center and to consider the range of learning modalities that enable the child to encounter and understand STEM concepts. The role of the university course is to support preservice teachers in making sense of the whole child and how concept building affects the design process, incorporating new pedagogies. This might include using documentation that records the learning outcomes and describes the pedagogies used. It is set in the context of multimodal learning, 


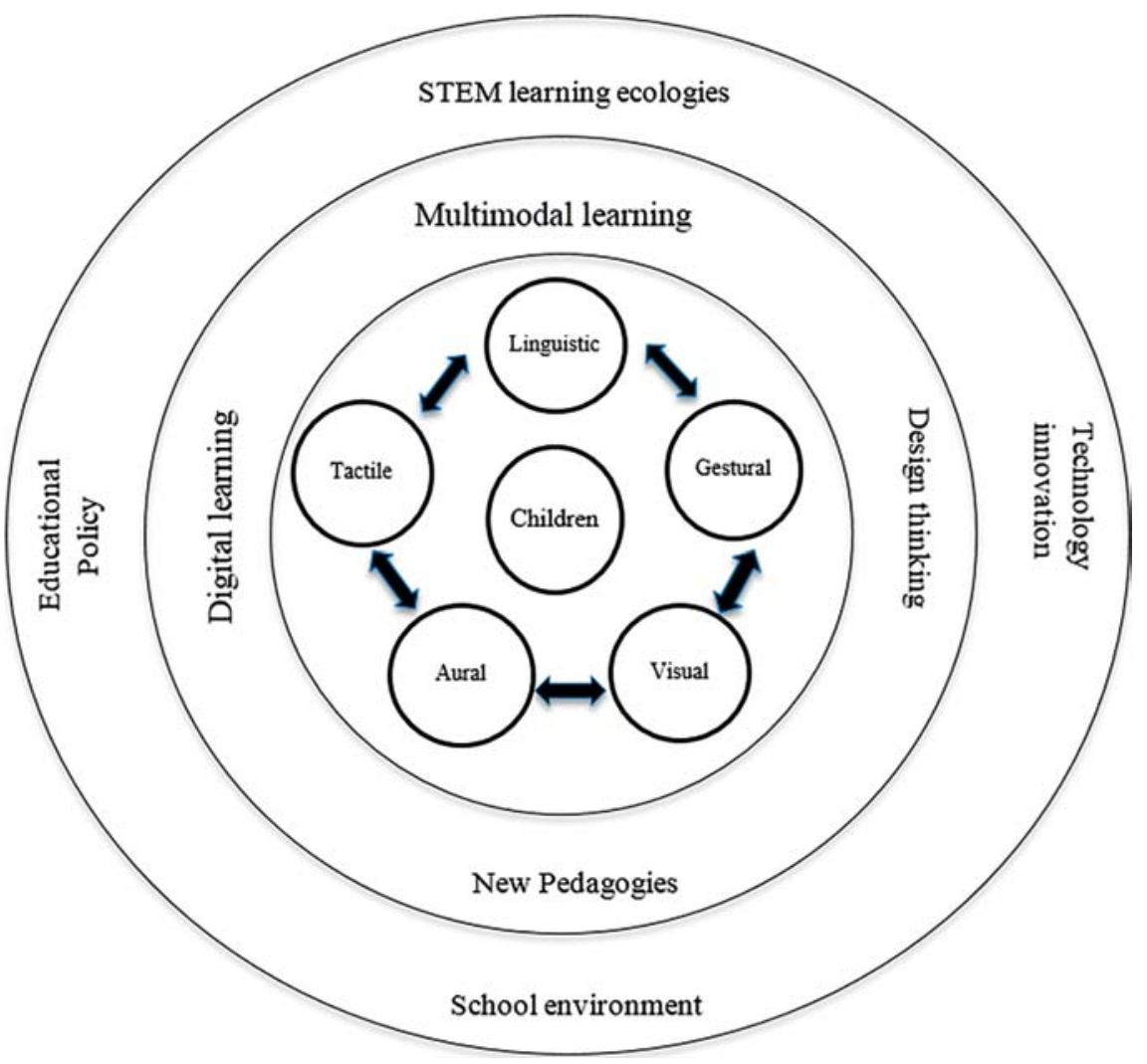

FIGURE 1 Changing learning ecologies in applying technology in early childhood teacher education.

which supports deep learning and engagement with ideas. The multimodal pedagogies are reflected in the use of digital technologies and design thinking to enable a project- or inquiry-based approach to learning. These elements are reflected in the second stage, which links and connects a holistic view for creating learning ecologies.

In this second stage, EC teachers' pedagogy should be supported and extended via modeling and extended practice during the course. The third stage considers the overarching themes that shape teaching and learning in early childhood education in Hong Kong, focusing on the policy imperatives that affect the school environment and the technological innovations that facilitate new STEM learning ecologies in which materials, people and ideas circulate and lead to new knowledge building and creation.

This authentic STEM learning is interdisciplinary and will connect to local classroom settings. Authentic STEM learning must have sufficient learning 
resources to allow children to explore, discover and innovate in their knowledge building. Limited STEM learning resources can be a barrier for EC teachers. The STEM Working Group paper (2017) provides general recommendations for selecting appropriate STEM resources; however, more specific guidance is needed to support EC teachers and school leaders in establishing contextspecific STEM classroom resources. Not all such resources need be digital; sometimes, the most effective resources are those that young children can touch and manipulate. The teacher education program should link with preschool settings to create two stages of study.

Designing such STEM learning spaces and resources will be an initial step in this change. In creating new learning ecologies, we focus on knowledge generation in authentic contexts that are multimodal and incorporates the use of new technologies where relevant. This might be challenging for teacher education programs that are traditionally subject driven. However, the real world knowledge is holistic and integrated, and it should thus support the impetus for changing learning ecologies.

\section{Reference}

Ainsa, T. (2013). Early childhood pre-service teachers' response to mobile technology: creative projects, analysis, and reflection on learning experiences.Education, 134(2), 161-166.

Alexander, C., KnezeK, G., Christensen, R., Tyler-Wood, T., \& Bull, G. (2014). The Impact of Project-Based Learning on Pre-Service Teachers' Technology Attitudes and Skills. Journal of Computers in Mathematics and Science Teaching, 33(3), 257-282. Waynesville, NC USA: Association for the Advancement of Computing in Education (AACE).

Bers, M., Seddighin, S., \& Sullivan, A. (2013). Ready for Robotics: Bringing together the $\mathrm{T}$ and $\mathrm{E}$ of STEM in early childhood teacher education. Journal of Technology and Teacher Education, 21(3), 355-377. Waynesville, NC USA: Society for Information Technology \& Teacher Education.

Blackwell, C.K., Lauricella, A.R., Wartella, E., Robb, M., \& Schomburg, R. (2013). Adoption and use of technology in early education. Computers \& Education, 69, 310-319. doi:10.1016/j.compedu.2013.07.024.

Buckleitner, W. (2009). Pocket Rockets: The past, present and future of children's portable computing. In A. Druin (Ed.) Mobile Technology for Children:Designing for Interaction and Learning (pp. 43-62). doi:10.1016/b978-0-12-374900-0.00o03-x.

Clements, D.H., Nastasi, B.K., \& Swaminathan, S. (1993). Young children and computers: Crossroads and directions from research. Young Children, 48(2), 56-64. 
Cuban, L. (2001). Oversold and underused: Computers in the classroom. Cambridge, MA: Harvard University Press.

Curriculum Development Council. (2006). Guide to the Pre-primary Curriculum. Hong Kong: Curriculum Development Council.

Curriculum Development Council. (2017). Kindergarten Education Curriculum Guide. Hong Kong: Curriculum Development Council.

Dong, C. (2018). Preschool teachers' perceptions and pedagogical practices: young children's use of ICT. Early Child Development and Care, 188(6), 635-650. doi: 10.1080/03004430.2016.1226293.

Early Childhood STEM Working Group. (2017). Early STEM matters: Providing highquality sT E M experiences for allyoung learners. Policy Report. Retrieved on November 20, 2018, from https://d3lwefg3pyezlb.cloudfront.net/docs/Early_STEM_Matters _FINAL.pdf.

Edwards, S. (2015). New concepts of play and the problem of technology, digital media and popular-culture integration with play-based learning in early childhood education. Technology, Pedagogy and Education, 25(4), 513-532. doi:10.1080/147593 9x.2015.1108929.

English, L.D. (2018). Learning while designing in a fourth-grade integrated STEM problem. International Journal of Technology and Design Education. doi:10.1007/ s10798-018-9482-z.

Ho, C.W.D. (2010). Teacher participation in curriculum and pedagogical decisions: Insights into curriculum leadership. Educational Management Administration \& Leadership, 38(5), 613-624. doi:10.1177/1741143210373739.

$\mathrm{Hu}, \mathrm{X} .$, \& Yelland, N. (2017). An investigation of preservice early childhood teachers' adoption of ICT in a teaching practicum context in Hong Kong. Journal of Early Childhood Teacher Education, 38(3), 259-274. doi:10.1080/10901027.2017 .1335664 .

King, D., \& English, L.D. (2016). Engineering design in the primary school: applying STE M concepts to build an optical instrument. International Journal of Science Education, 38(18), 2762-2794. doi:10.1080/09500693.2016.1262567.

Marsh, J., Plowman, L., Yamada-Rice, D., Bishop, J., \& Scott, F. (2016). Digital play: a new classification. Early Years, 36(3), 242-253. doi:10.1080/09575146.2016.1167675.

NAEYC \& Fred Rogers Center for Early Learning and Children's Media. (2012). Technology and interactive media as tools in early childhood programs serving children from birth through age 8. Washington, DC: NAEYC; Latrobe, PA: Fred Rogers Center for Early Learning at Saint Vincent College. Retrieved on November 22, 2013, from www. naeyc.org/files/naeyc/file/positions/PS_technology_WEB2.pdf.

Plowman, L., \& Stephen, C. (2003). A "benign addition"? Research on ict and preschool children. Journal of Computer Assisted Learning, 19(2), 149-164. doi: 10.1046/j.0266-4909.2003.00016.x. 
Plowman, L., \& Stephen, C. (2007). Guided interaction in pre-school settings. Journal of Computer Assisted Learning, 23(1), 14-26. doi:10.1111/j.1365-2729.2007.00194.x.

Plowman, L., Stephen, C., \& McPake, J. (2010). Growing up with technology: Young children learning in a digital world. London: Routledge. doi:10.4324/9780203863619.

Rosen, D.B., \& Jaruszewicz, C. (2009). Developmentally Appropriate Technology Use and Early Childhood Teacher Education.Journal of Early Childhood Teacher Education, 30(2), 162-171. doi:10.1080/10901020902886511.

Siraj-Blatchford, I., \& Siraj-Blatchford, J. (2006). A guide to developing the ICT curriculum for early childhood education. Stoke on Trent: Trentham Books.

Weng, J., \& Li, H. (2018). Early technology education in China: A case study of Shanghai. Early Child Development and Care, 1-12. doi:10.1080/03004430.2018.1542383.

Yelland, N., Drake, P., \& Sadler, K. (2017). Early Learning in STEM: Multimodal learning in the 21st century. Project Report. Victoria University, Melbourne. Retrieved on September 29, 2018, from https:/docs.education.gov.au/documents/ early-learning-stem-multimodal-learning-21st-century. 